\title{
FORECASTING OF WHEEL CLOGGING BY CONTINUOUS TEMPERATURE MONITORING IN LOCOMOTIVES
}

\author{
Harikrishnan E. \\ Department of Electrical and Electronics \\ Engineering \\ NSS College of Engineering \\ Palakkad, India \\ Haritha T.R. \\ Department of Electrical and Electronics \\ Engineering \\ NSS College of Engineering \\ Palakkad, India
}

\begin{abstract}
In any country, millions of people depend upon railway network to travel. Any change or problem in the network will disrupt many people's life. Rail accidents are one of the most serious problem faced by the rail industry. Majority of the rail accidents are caused by derailment. The health and condition of axle box plays a major role. Rapid heating of axle box causes rapid deformation of the wheel axle. This can be caused due to several reasons starting from any impurities in the lubricant used, insufficient operating clearance, long duration of operation etc. this maneuver can cause derailment or fire on the locomotive. It is not an everyday occurrence but even a minuscule probability cannot be neglected considering what level of destruction it can cause. The present system of detecting the hot axle box is completely manual. This paper presents an automatic diagnostic tool that will replace the manual and erroneous method of detection. The paper aims to provide a real time display to the locomotive cabin along with an alert system. Provision for logging of the sensor data is also given, that will be useful for further references.
\end{abstract}

Keywords-Hot axle box, Resistance Temperature Device, Grease slit, Liquid Crystal Display, Arduino, Hot axle box.

\section{INTRODUCTION}

In any country, the biggest mode of transportation will be public transport. In India, Railways is the most popular mode owing to the cheapness and reliability. Indian Railway network on a daily basis facilitates transportation of more than 23 million people of the country[1]. The bogies weighing over 1000 tonnes are carried by massive wheel assembly run by a locomotive that is electrical or mechanical [2]. There are precisely designed wheel sets with bearing and suspension that makes the journey smooth. Just like every mode of transportation it accompanies with accidents related

\author{
Lavanya V. \\ Department of Electrical and Electronics \\ Engineering \\ NSS College of Engineering \\ Palakkad, India \\ Greeshma \\ Department of Electrical and Electronics \\ Engineering \\ NSS College of Engineering \\ Palakkad, India
}

to that mode of transport. Majority of the rail accidents are caused by derailment [3].

Train derailment may be triggered by the rail carts (bogies) or by the locomotive. Train derailments due to derailed locomotive is more severe than the cart derailment in terms of impact and loss caused. Derailments can be a caused due to numerous reasons, of which, the main three are:

a) Careless mistakes on the side of the loco pilot.

Loco pilots are the human hand behind the humongous machines which deliver 6000 to $12,000 \mathrm{H}$. P. considering human errors intentional or unintentional can possibly derail the locomotive. Sleep monitoring devices and emergency brake devices are now incorporated in modern locomotives to reduce this error.

b) Crack on the rail track or deformed rail track.

Trains run on carefully designed and maintained parallel rails called tracks devoted on dependable surfaces including boulders or concreate structures. The clearance is carefully maintained along with the slope. Any alteration to this predefined clearance can topple the train.

c) Fault with the rolling stock (the axle and bearings).

These may be either deformation of the wheel shape due to various reasons or wheel clogging. Sudden interruption to smooth functioning of the axle or wheel at speeds above $40 \mathrm{mph}$ can cause rapid jerks capable of derailing the locomotive [4].

Wheel set comprises of two wheels rigidly connected by an axle. This axle is supported by bearings mounted on the axle journals. This arrangement provides the necessary distance between the vehicle and the rail track[5][6]. This bearing set-up is housed in a metal box called axle-box which assists the lubrication of the bearings. Directly connected to the wheel set and the bogie frame is the axle box containing the axle box bearing system. The axle box 


\section{International Journal of Engineering Applied Sciences and Technology, 2020 Vol. 4, Issue 10, ISSN No. 2455-2143, Pages 109-115 \\ Published Online February 2020 in IJEAST (http://www.ijeast.com)}

acts a plinth structure for subsystems and components such as primary and secondary spring systems, axle box guidance unit, damper units, steering mechanisms of wheel sets, earth return devices as well as sensors to detect operational parameters of axle, wheel and bogie monitoring systems[5][6].

In short, the axle box is the metal case that allows the wheel set to rotate by providing the bearing housing and the mountings for the primary suspension of the locomotive to attach the wheel set to the bogie or vehicle frame. The axle box transmits longitudinal, lateral, and vertical forces from the wheel set on to the other locomotive or bogie elements.

\section{Hot AXLE BoX}

The axles, bearings and axle box are subjected to the most load and they are the most important parts which keep the train steady and moving. Temperature of the axle box is an important parameter that is used to identify any technical disorder in the axles or bearings. The normal operation of axle box is characterized by balance of heat exchange between wheel set and the lubricant, axle box temperature and atmospheric air temperature [4].

\section{A. Causes}

Axle journal temperature when the train is running at the uninterrupted regime depends on the type and dimensions of bearings, anti-frictional and hydrodynamic properties of the lubricant, spaces between the bearing rollers and rings, static and dynamical loads of the bearing, train running speed, duration of travel without stops, and ambient air temperature, and the road curves [7].

Friction of axle-box node parts results in the heating of their surfaces. Upon reaching the limit values of axle temperature this heating causes structural changes in the upper surfaces of the bearing parts while change in dimension of axle roller, due to which the rollers may become clogged. This happens because metals have a property to expand on heating. Axle bearings and axle limb being made of metal, on excessive heating due to friction, it undergoes change in its dimensions and hence reduces the standard clearance between the two. This results in more friction between the two which causes a cyclic dimension and temperature rise and causing axle clogging within the bearings.

Axle-box heating and itemizations may be subdivided into four main groups: poor lubrication, fatigue, not qualitative mounting and contamination (with metal admixtures, water). Bearing damage occurs mainly due to improper lubrication excessive load, excessive rotation (speed), inadequate mechanical properties which include insufficient operating clearance between axle limb and bearings, radial stress caused by an external heat source, obstructed axle run due to the breaking of the cage, initial damage of the bearing at time of installation or during running.

The damage of axle box bearing mechanisms could be classified into two types: brinelling and spalling [8]. Brinelling consists of one or more indentations distributed over the entire raceway circumference that is subjected to static overloading [9]. Each such indentation acts like a small fatigue site, thus producing sharp impacts with the passage of the rolling element in every cycle, eventually leading to the development of spalling at the indentation sites as the bearing continues to operate under every cycle of rotation or motion of the locomotive. Under normal loading conditions, the bearing will form several minute cracks due to material fatigue after certain duration of usage. With an increase in size during cyclic loading, the cracks deepens and progresses to the surface and are manifested as spalling in the contact areas [10]. Breakdown of rolling stock axle-boxes if not detected in due time may cause a rail accident by an axle box explosion, fire or derailment of the locomotive.

\section{B. Current Methods of Monitoring}

The present system of detection is manual and this increases risk of it going unnoticed, leading to disaster. These methods include visual inspection, IR Gun temperature monitoring etc. In visual inspection the person assigned does visual inspection of random axles and observes the axle color, smell and physical condition; if any abnormality is observed it is reported. But this method is heavily dependent on the mood and sincerity of the person involved, weather conditions and lighting conditions. Whereas in IR Gun temperature measurement the person fires the IR gun at the locomotive and bogie axles to observe the surface temperature reading of the axle boxes. This method is more scientific than visual inspection. Main drawbacks of IR Gun temperature monitoring system are that its very time consuming and the non-linearity in temperature monitoring based on firing distance of the IR Gun[2][11].

\section{KEY POINTS TO SYSTEM DESIGN}

The aim of the system is to create an automatic diagnostic tool that will be able to continuously monitor the temperature of the axle box and detect any abnormal rise in the temperature that is usually an indication of bearing failure and bring this into notice to the person concerned at the earliest. The following points are to be considered before designing the system:

- The axle is a rotating element over which, the bearings are housed and it is protected from the surrounding using a metal casing called the axle box. The actual axle temperature is at the intersection between the axle and the bearings. For accurate results, the sensing position of the temperature sensor should be as close as possible to this hotspot.

- Accessing the core of axle box without altering the existing physical structure of the axle box to measure the temperature is a hurdle. The only vent in the axle box structure is a grease slit. The diameter of the grease slit is $8 \mathrm{~mm}$. The temperature sensor needs to be small enough to fit into this slit.

- Positioning of temperature sensor should not affect the clearance provided by manufacturers to various moving parts of the locomotive. 


\section{International Journal of Engineering Applied Sciences and Technology, 2020 \\ Vol. 4, Issue 10, ISSN No. 2455-2143, Pages 109-115 \\ Published Online February 2020 in IJEAST (http://www.ijeast.com)}

\section{STRUCTURE OF THE SYSTEM}

By analysing the different practical constraints, the simplest system for measurement of axle box temperature is proposed in this paper. The basic block diagram of the system is given in Figure 1 and each of the blocks are explained below.

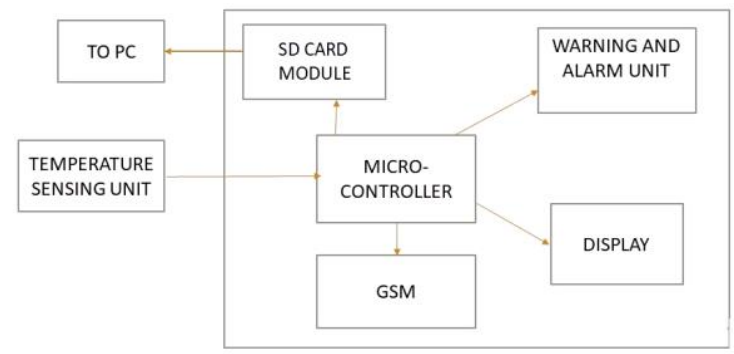

Figure 1: Basic block diagram of the proposed system

\section{A. Temperature sensing unit}

The primary investigation was aimed at selection of temperature sensor and type. Various type of temperature sensors available in market include IR sensors, optical sensors, thermistors, thermocouples, RTD temperature sensors and semi-conductor devices. Optical based sensors were incompetent on the stage due to presence of lubricant which causes a heavy refraction to the electromagnetic wave (IR ray). Hence it was obvious that the necessity could be fulfilled only by surface contact temperature sensing mechanism. The best available remedy for the same was to make use of a Resistance Temperature Detector sensors. RTD sensors has the advantages of high accuracy, high precision and wide operating range. It also abides by the space constrain of having to fit into the $8 \mathrm{~mm}$ wide grease slit of the axle box.

Table I : Calibration data of RTD with Mercury thermometer

\begin{tabular}{|c|c|c|}
\hline $\begin{array}{c}\text { Type \& nature } \\
\text { of the subject }\end{array}$ & $\begin{array}{c}\text { RTD Measured } \\
\text { value }\end{array}$ & $\begin{array}{c}\text { Mercury } \\
\text { thermometer } \\
\text { value }\end{array}$ \\
\hline Drinking Water & 31.31 & 31 \\
\hline Pipe Water & 32.9 & 33 \\
\hline Cold Water & 20.32 & 20 \\
\hline $\begin{array}{c}\text { Water close to } \\
\text { boiling }\end{array}$ & 77.06 & 77 \\
\hline Hot water & 65.24 & 65 \\
\hline
\end{tabular}

The Calibration data of the Resistance Temperature Detector is given in table 1 , where it is calibrated with the normal mercury bulb thermometer.

\section{B. Arduino Uno}

The Arduino Uno is a microcontroller unit based on ATmega 328. ATmega 328 is an Atmel based single chip microcontroller part of megaAVR family. Arduino Uno has 14 digital input/output pins of which 6 can be used as Pulse Width Modulated outputs, along with 6 analog inputs, a 16 $\mathrm{MHz}$ ceramic resonator, a USB connection, a power jack, an Internal Circuit Serial Programming header, and a reset button. It contains everything needed to support the microcontroller including an auto driver installer. The Uno differs from all preceding boards in that it does not use the USB-to-serial driver chip. Instead, it features the Atmega16U2 programmed module as a USB-to-serial converter. The Arduino Uno can be powered via the USB connection or with an external power supply using a power adapter. The power source is selected automatically. External (non-USB) power can come either from an AC-to-DC adapter (wall-mount) or a battery. The adapter can be connected by plug adapter-a $2.1 \mathrm{~mm}$ center-positive plug into the board's power jack. The board is capable to operate on external supply of 6 to 20 volts. The main advantages of using Arduino Uno is its low cost, ease of programming, simplicity, its compatibility with different operating systems (Cross platform), its hardware and software being open source and extensible and large number of ports for its operation.

\section{Display and Alert system}

a) Display : The temperature measured is displayed inside the locomotive cabin using a 16x2 Liquid Crystal Display. Its operating voltage range is $4.7 \mathrm{~V}$ to $5.3 \mathrm{~V}$, which can be provided from the Arduino board. It consists of 2 rows and each row can print 16 characters. Each character is built by $5 \times 8$ pixel box. It has the ability to work on both 4 bit as well as 8 bit.
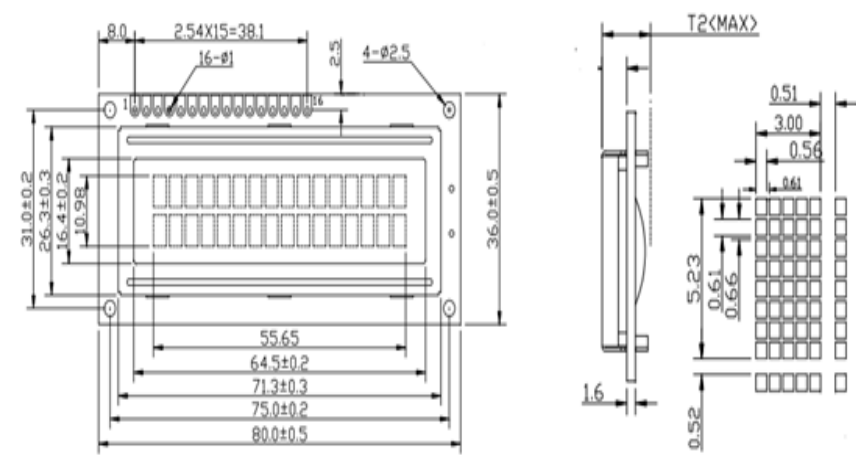

Figure 2: 16x2 Liquid Crystal Display

b) Alert System:There are mainly two different systems for alerting when the temperature rises beyond the specified limit of $120^{\circ} \mathrm{C}$.

\section{Hazard Warning Light}

The unit provides a red warning Light that will be triggered when the temperature goes above the upper limit specified as per the uploaded program. This is to the draw 


\section{International Journal of Engineering Applied Sciences and Technology, 2020 \\ Vol. 4, Issue 10, ISSN No. 2455-2143, Pages 109-115 \\ Published Online February 2020 in IJEAST (http://www.ijeast.com)}

the attention of the loco pilot towards the rise in temperature of axle box so that the wheels can be monitored before it progresses to the successive stages of damage.

\section{GSM Module}

Another type of warning system includes the use of GSM module (Figure 3) that sends a short message when the temperature rises beyond the limited value. The message will be sent to the respective loco shed where it can be documented and referred when the loco goes in for its fortnight maintenance. SIM 900 is a quad band (850, 900, $1800,1900 \mathrm{MHz}$ ) module. Its operational temperature range is from $-30^{\circ} \mathrm{C}$ to $70^{\circ} \mathrm{C}$. It requires a power supply of $3.4 \mathrm{~V}$ to $4.5 \mathrm{~V}$.

\section{Digital Card Module}

The temperature sensor data is processed by the Arduino module and the data is saved in a Secure Digital card (figure 4). The Secure Digital card is interfaced to the microcontroller using a Secure Digital card module. The module has Serial Peripheral Interface that is compatible with Arduino UNO. It makes use of $5 \mathrm{~V}$ or $3.3 \mathrm{~V}$ power supply. The Secure Digital card allows mass storage and data logging. The data logged can be transferred to a computer for further references.

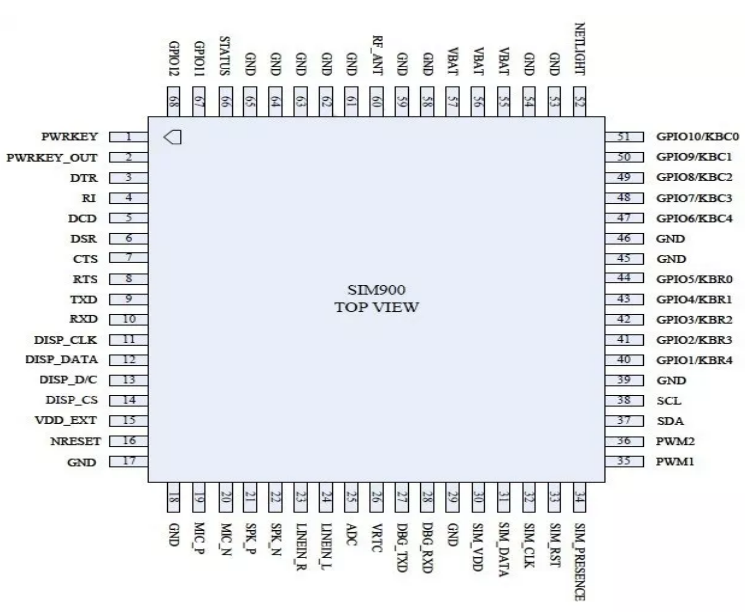

Figure 4: GSM Module

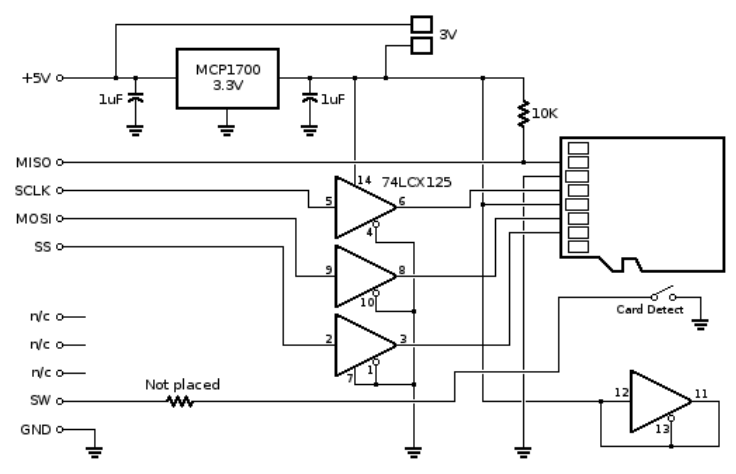

Figure 5: Secure Digital card module

\section{WORKING OF THE SYSTEM}

The RTD temperature sensor that is placed in the grease slit with the help of a modified grease nipple (figure 6 ), which measures the temperature of the grease. This modified grease nipple includes a RTD module within the nipple. This temperature value is processed by the microcontroller Arduino UNO. This processed data is sent to SD card module based on counter frequency and the temperature value is displayed inside the cabin of locomotive. Also, the temperature data is logged every 10 minutes and saved in comma- separated values file format into a Secure Digital card. This data can be accessed from any computer via the Secure Digital Card. Also, the microcontroller will trigger the warning system if the temperature measured by the sensor is found to be greater than $100^{\circ} \mathrm{C}$ (or the temperature set by the locopilot). The warning system includes a hazard warning light and a short service message sending module. The hazard warning light plays the role of capturing the attention of the loco pilot towards the impending bearing failure at an earlier stage of abnormal temperature rise. The schematic flowchart and circuit diagram of the proposed module is shown in figure 7 and figure 8 .

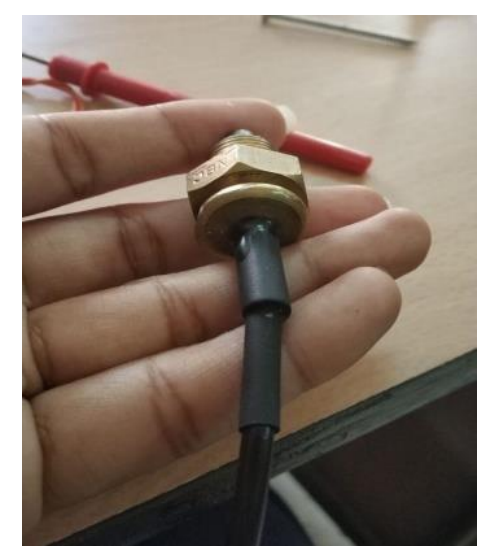

Figure 6: Modified grease nipple

The temperature from the sensor which is digital in nature, is read and processed in the microcontroller. This data is then saved into the Secure Data Card (SD Card). Then the microcontroller checks if the day count has exceeded 15 days. This system is designed for an perational period of a fortnight, as it is the time frame taken by the loco to return to the loco shed for maintenance. If it finds out that day count is greater than 15 , the operation of saving data into the secure digital card is terminated. If not, it will check if the temperature value is greater than $100^{\circ}$ Celsius. If found positive, then it will trigger the warning light that is suitably positioned inside the locomotive cabin to warn the loco pilot about the abnormal temperature rise. Then it checks if the temperature is greater than $125^{\circ}$ Celsius. If found positive, it will send a warning S.M.S. which will have the information about the locomotive, to the loco shed. 


\section{International Journal of Engineering Applied Sciences and Technology, 2020 \\ Vol. 4, Issue 10, ISSN No. 2455-2143, Pages 109-115 \\ Published Online February 2020 in IJEAST (http://www.ijeast.com)}

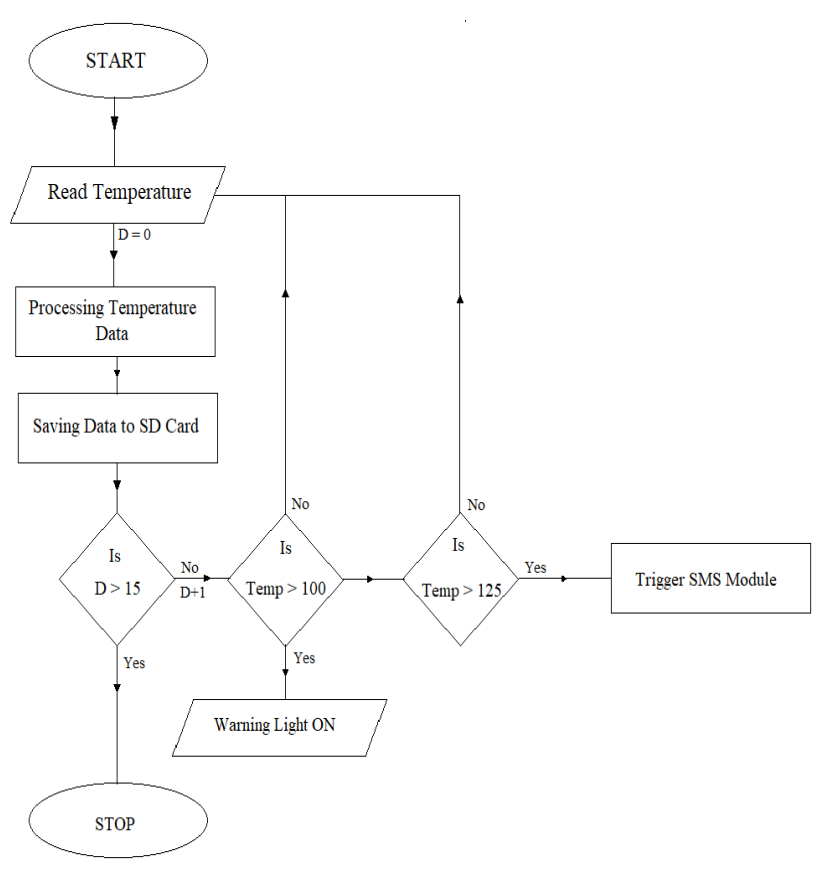

Figure 7: Algorithm of the system

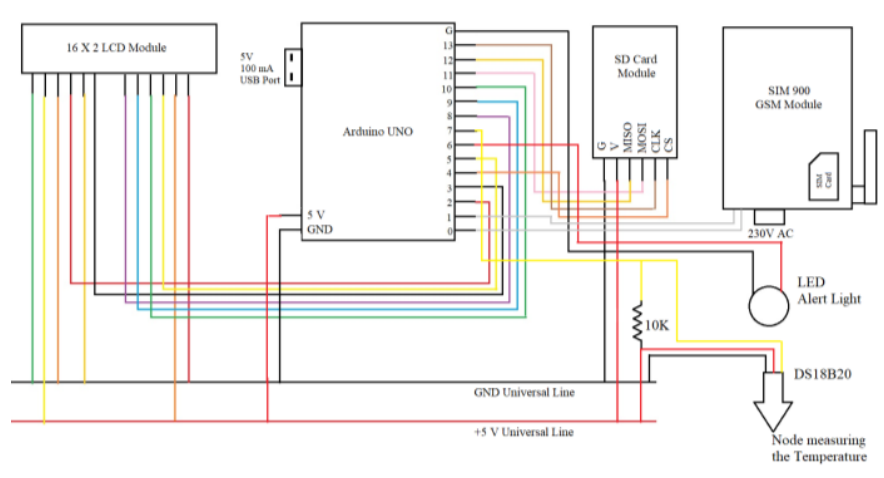

Figure 8: Circuit Diagram

a) Sensing Unit: In DS18B20, temperature measurements are done using a two band-gap-generated voltage sources. First voltage source has a high-temperature coefficient and it changes deterministically across temperature. The second voltage source has a low-temperature coefficient and does not change across temperature. The analog-to-digital converter (ADC) converts this difference between two voltages to a digital value, which represents the temperature of the device.

- Power supply range is $3.0 \mathrm{~V}$ to $5.5 \mathrm{~V}$.

- Measures temperatures from $-55^{\circ} \mathrm{C}$ to $+125^{\circ} \mathrm{C}$.

- $\pm 0.5^{\circ} \mathrm{C}$ accuracy from $-10^{\circ} \mathrm{C}$ to $+130^{\circ} \mathrm{C}$.

- Converts 12-bit temperature to digital word in $750 \mathrm{~ms}$

- Capable to be powered from data line

b) Microcontroller: The Arduino Uno uses an Atmega 328 microcontroller. Hence it has 14 digital input or output pins of which six pins are capable to be used as pulse width modulated (PWM) outputs, along with six analog inputs. Arduino Uno is clocked by a $16 \mathrm{MHz}$ crystal oscillator. It also accosiates an USB connection port, an AC power jack, an ICSP header, DC power pin and a reset button. The Uno module contains everything needed to support the microcontroller to enable it as a standalone module by simply connecting it to a computer with a USB cable or power it with a AC-to-DC adapter or battery. The Uno stands different from its preceding boards in that it does not use the FTDI-USB to-serial driver chip, instead it comes with a Atmega 8U2 programmed module as a USB-to-serial converter.

c) Storage Unit: The micro SD (Secure Digital) Card Module is a simple solution for transferring data to and from a standard SD card (figure 5). The pin out is compatible with Arduino without any other interface, but can also be used with other microcontrollers. It allows you to add mass storage and data logging to the project. This module has SPI interface which is compatible with any Secure Digital card and it use $5 \mathrm{~V}$ or $3.3 \mathrm{~V}$ power supply which is compatible with Arduino UNO/Mega. This module helps in expand the capability an Arduino can do with its poor limited memory.

d) Display Unit: The display unit used is Liquid Crystal Display (LCD) $16 \times 2$. LCD (Liquid Crystal Display) screen is an electronic display module and has a wide range of applications and $16 \times 2$ LCD display is a basic display module. The selection of LCD module was based upon its following features:

- Economical

- Easily programmable

- Have no limitation of displaying special characters

- Ability to display even custom characters (unlike in seven segments)

- Ability to incorporate animations.

- Compatibility with microcontrollers like Arduino

e) GSM Unit: The SIM900 GSM module is a complete Quad-band GSM/GPRS solution in a SMT module which can be embedded in the customer applications. Featuring an industry-standard interface, the SIM900 delivers GSM/GPRS 850/900/1800/1900MHz performance for voice, SMS, Data, and Fax in a small form factor and with low power consumption.

\section{RESUlTS AND DISCUSSION}

As the project is aimed at developing an ideal solution for an industrial problem, it is necessary to test the prototype developed in the real time situations. Our prototype is focused on creating a solution for monitoring the axle box temperature of a locomotive. As the prototype was developed, it was necessary to verify its performance in real time conditions it was designed for, rather than laboratory tests. The final and most important part of the project was to test the prototype in a live running locomotive. In order to test, the project was taken to the Electric Loco Shed, Erode. Obtaining permission to attach our sensor onto a locomotive was not an easy task. After an hour long presentation and discussion with the Senior Divisional Electrical Engineer of 


\section{International Journal of Engineering Applied Sciences and Technology, 2020 \\ Vol. 4, Issue 10, ISSN No. 2455-2143, Pages 109-115 \\ Published Online February 2020 in IJEAST (http://www.ijeast.com)}

Electric Locoshed, Erode. We obtained permission to test the developed prototype on an electric locomotive. A WAG7 (Indian) locomotive which had arrived for scheduled maintenance, was allotted to us for testing our project. With the help of a technician in the electric locoshed, the temperature sensor along with the bolt was inserted in the grease slit of the cabin two left axle box. The functional unit was placed in the locomotive cabin, which monitors the change in temperature of the axle box, and functions the precautionary measures if the axle box temperature rises abnormally. The locomotive was moved along a distance of $1.5 \mathrm{~km}$ and at the starting point the temperature of the axle box was noted as $35.19^{\circ} \mathrm{C}$.

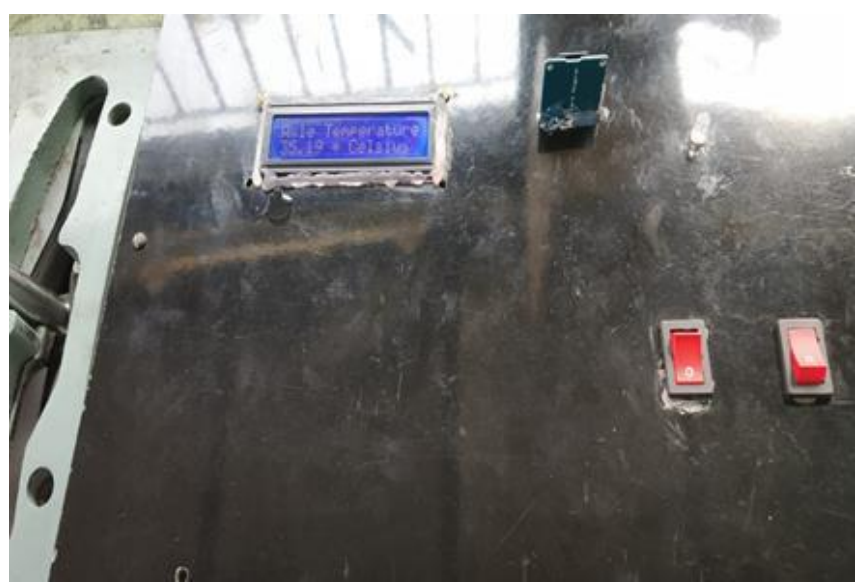

Figure 9: Module unit with display

Once the loco started its motion a gradual change in the grease temperature was observed. The following table of temperature variation with respect to distance covered was obtained when the locomotive WAG7 (Indian) (figure 11), was ran at an average speed of $20 \mathrm{~km} / \mathrm{hr}$.

Table 2: Axle box temperature change noted at the time of testing

\begin{tabular}{|l|c|c|c|c|}
\hline Distance & $100 \mathrm{~m}$ & $500 \mathrm{~m}$ & $1000 \mathrm{~m}$ & $1500 \mathrm{~m}$ \\
\hline Temp. & $35.19^{\circ} \mathrm{C}$ & $35.19^{\circ} \mathrm{C}$ & $35.25^{\circ} \mathrm{C}$ & $35.38^{\circ} \mathrm{C}$ \\
\hline
\end{tabular}

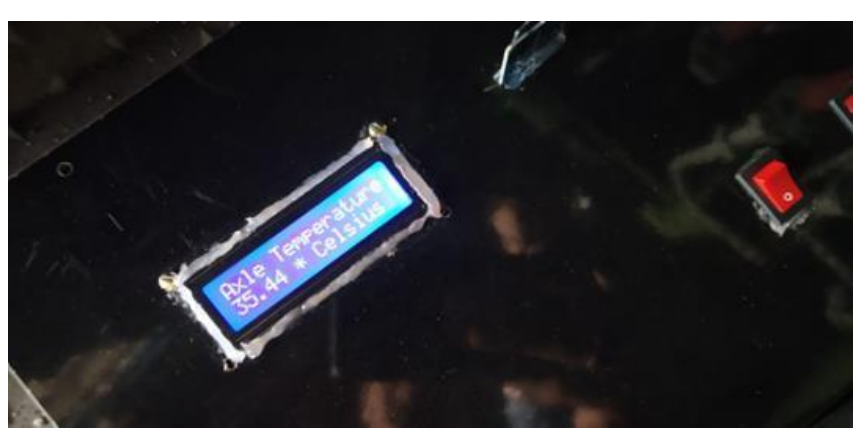

Figure 10: Display of axle temperature

Drastic temperature changes were not observed as the locomotive speed was way below par average speed and the distance covered was microscopic in nature with respect to average distance covered by a locomotive on an average run[13][14].

\section{CONCLUSION AND FUTURE WORK}

Rail networks are huge systems with thousands of trains and millions of passengers. Any disruptions caused in the running schedule will disturb many who depend on it. The project work undertaken to introduce a new automated system of hot axle box diagnosis is a very simple and straight forward one. The application of this into the locomotives will help in early detection of the hot axle box, which is an indicator of bearing failure. This system will help to reduce the chance of derailment and fire caused by bearing failure. The project work undertaken is a prototype being created for a single wheel of the locomotive. The project can be extended to all the 6 Wheels of the locomotive.

\section{ACKNOWLEDGMENT}

We express our deep gratitude towards all the officials and staffs of Electric locoshed, Erode and we are also grateful to C.E.R.D Trivandrum for funding our project. We also like to thank Dr. Vasanthi V. for mentoring us and without whom this would not have been possible.

\section{VIII.REFERENCES}

[1] https://www.business-standard.com/article/beyondbusiness/18 interesting-facts-about-indiarailwaysbusiness-standard-news-115021600404_1.html

[2] https://www.irfca.org/faq/faq-stock3.html

[3] https://factly.in/indian-railway-accidents-statisticsreview-last-5-years/

[4] LUNYS, Olegas \& DAILYDKA, Stasys \& Bureika, Gintautas. (2015). Investigation on features and tendencies of axle-box heating. Transport Problems : an International Scientific Journal. 10. 105-114. 10.21307/tp-2015-011.

[5] "Specification for Axle Box Assemblies with Axle Journal Bearings for Diesel \& Electric Locomotives" Manual published by Research Design and Standards Organisation, Ministry of Railways, Government of India.

[6] INDRA REDDY, P.SRINIVASA KUMAR, (June 2015) "Design and Dynamic Analysis of Locomotive Wheel Axle" A. International Journal of Science, Engineering and Technology Research (IJSETR), Volume 4, Issue 6, 2293 ISSN: $2278-7798$

[7] Gerdun, V., Sedmak T., Sinkovec V., Kovse I., Cene B. (2007) "Failures of bearings and axles in railway freight wagons." Engineering Failure Analysis. 2007. Vol.14(5).P.884-894.

[8] Choe, H.C. \& Wan, Y. \& Chan, A.K. "Neural pattern identification of railroad wheel-bearing faults from audible acoustic signals: comparison of FFT, CWT, and DWT features." Available at: http://www.ece.tamu.edu/ akchan/Demo/paper_97.pdf. 


\section{International Journal of Engineering Applied Sciences and Technology, 2020 \\ Vol. 4, Issue 10, ISSN No. 2455-2143, Pages 109-115 \\ Published Online February 2020 in IJEAST (http://www.ijeast.com)}

[9] Howard, I. "A review of rolling element bearing vibration Detection, Diagnosis and Prognosis." Australia: DSTO Aeronautical and maritime Research Laboratory. 1994.

[10] Holm-Hansen, B.T. \& Gao, R.X. (2000) Structural design and analysis for a sensor-integrated ball bearing. "Finite Elements in Analysis and Design." . Vol. 34(34). P. 257-270.

[11] Lee, J. S., Choi, S., Kim, S. S., Park, C., \& Kim, Y. G. (2011). A mixed filtering approach for track condition monitoring using accelerometers on the axle box and bogie. IEEE Transactions on Instrumentation and Measurement, 61(3), 749-758.

[12] Hoddinott, D. S. (2004). Railway axle failure investigations and fatigue crack growth monitoring of an axle. Proceedings of the Institution of Mechanical Engineers, Part F: Journal of Rail and Rapid Transit, 218(4), 283-292.

[13] Chudzikiewicz, A., Bogacz, R., Kostrzewski, M., \& Konowrocki, R. (2018). Condition monitoring of railway track systems by using acceleration signals on wheelset axle-boxes. Transport, 33(2), 555-566.

[14] Oregui, M., Li, S., Núñez, A., Li, Z., Carroll, R., \& Dollevoet, R. (2017). Monitoring bolt tightness of rail joints using axle box acceleration measurements. Structural Control and Health Monitoring, 24(2), e1848. 